\title{
Natural Selection Intensity among Kapu Caste Population of Coastal Andhra Pradesh, India
}

\author{
E. Raju and D.S.R.S.Prakash \\ Department of Biotechnology, Godavari Institute of Engineering \& Technology, Rajahmundry \\ 533 294, East Godavari District, Andhra Pradesh, India
}

KEYWORDS Natural Selection. Fertility. Mortality. Caste. Andhra Pradesh

\begin{abstract}
The selection intensity indices were computed based on the demographic information pertaining to fertility and mortality among the Kapu, an endogamous caste population of Andhra Pradesh. The indices were computed by original formula of Crow and modified formula of Johnston and Kensinger. The total fertility and mortality indices are slightly higher than other Andhra populations studied earlier. In the present population, the selection is manifested mainly through differential fertility rather than mortality, which is a deviation from general trend.
\end{abstract}

\section{INTRODUCTION}

Natural selection is a principal driving force of evolution. Natural selection operates through differential mortality and fertility among human populations. The differential mortality acts on individuals prior to their reproductive age, and determines that group of individuals who survive and may potentially produce the offspring to constitute the next generation of a population. Darwin's "survival of the fittest" refers to the differential mortality of individuals within a species and includes the selection agent of differential fertility. It is probable that natural selection operating through differential mortality is less important among modern human populations where differential fertility appears to be the more effective agent. According to the Fisher's "fundamental theorem of natural selection", the rate of increase of fitness of any organism at any time is equal to its genetic variation in fitness at that time (Fisher 1958). Based on these concepts, Crow (1958) devised an index $\left(\mathrm{I}_{\mathrm{f}}\right)$ of the opportunity for natural selection to quantify the influence of selection inherent in evolutionary process, and it is partitioned into two components (due to mortality prior to the reproductive age and due to differences in fertility among women who have reached reproductive age). Later, Johnston and Kensinger's (1971) revised the computation of the index by considering the prenatal mortality also. The present paper reports the intensity of selection in terms of Crow's as well as Johnston and Kensinger's indices among the Kapu, an endogamous caste population of coastal Andhra
Pradesh. Kapu, an agricultural caste distributed in almost all districts, is one of the dominant castes of Andhra Pradesh.

\section{MATERIALS AND METHODS}

The paper is based on the demographic data collected from 101 married women of Kapu caste, living in rural and semi urban areas of West Godavari district of Andhra Pradesh. The demographic information pertaining to fertility and mortality was obtained through personnel interviews using a pre-tested schedule. The collected data covers the mortality rates at both prenatal (abortions and still births) and postnatal mortality (childhood/pre-reproductive deaths). In the present study, indices of opportunity for natural selection were computed based on original formula of Crow (1958) and modified formula of Johnston and Kensinger (1971).

\section{RESULTS AND DISCUSSION}

The indices of intensity of selection based on the methods of Crow as well as Johnston and Kensinger' among the Kapu are presented in Table 1. Crow's total index of opportunity for natural selection is 0.5348 . The components of fertility and mortality are 0.4924 and 0.0424 , respectively. The contribution of fertility to the total index is greater than the contribution of mortality. The total index based on Johnston and Kensinger's method (0.5927) is slightly higher than the index of Crow (0.5348), due to the additional contribution of prenatal mortality. The fertility component is 0.4758 . The contribution 
Table 1: Indices of opportunity for natural selection intensity among Kapu population of coastal Andhra Pradesh

\begin{tabular}{ll}
\hline Selection component & Value \\
\hline
\end{tabular}

Crow's Index

Mortality component $\left(\mathrm{I}_{\mathrm{m}}\right) \quad 0.0424$

Fertility component (I)

Total Index $\left(\mathrm{I}_{\mathrm{r}}\right) \quad 0.5348$

Percentage of fertility component $\quad 92.07$

Percentage of mortality component $\quad 7.93$

Johnston and Kensinger's Index

Prenatal mortality component $(\mathrm{I}) \quad 0.0745$

Postnatal mortality Component $\left(\mathrm{I}_{\mathrm{mc}}\right)$

Fertility Component $\left(\mathrm{I}_{\mathrm{f}}\right) \quad 0.4758$

Total index (I) 0.5927

Percentage of fertility component $\quad 80.28$

Percentage of prenatal mortality component 12.57

Percentage of postnatal mortality component 7.15

of prenatal mortality $(0.0745)$ is more than the contribution of postnatal contribution (0.0424). This trend is unusual as in majority of populations, the postnatal mortality contribute more than prenatal mortality to the total index of opportunity of natural selection (Reddy and Chopra 1990). Also, in the present population, the selection is mainly manifested through the fertility, rather than mortality. Studies from India and elsewhere indicated that mortality contribute heavily to the total selection among tribal, pre-agrarian and agrarian populations. While in developed and industrialized societies, the contribution of mortality is low and selection is mainly manifested through fertility (Spuhler 1976; Reddy and Chopra 1990). However, several of the recent studies undertaken among tribal and rural agrarian populations reported the lower contribution of mortality and inferred that the natural selection is manifested mainly through the fertility (Babu et al. 1995; Babu and Kusuma 2002; Bhasin and Kshatriya 1990; Bhasin and Nag 2002, 2007; Reddy and Reddy 1984; Reddy et al. 1987; Sudhakar et al. 1998). Probably the influence of lower fertility rates and accessibility to health care may be responsible for the changing trend, i.e., lower contribution of mortality. Changing fertility and mortality patterns due to major socioeconomic development have a profound effect on natural selection in human population (Cavalla-Sforza and Bodmer 1971).

\section{REFERENCES}

Babu BV, Kusuma YS, Naidu JM 1995. Opportunity for natural selection among four Andhra caste populations. J Hum Ecol, 6: 63-64.

Babu BV, Kusuma YS 2002. Demographic structure and its implications among two breeding isolates of Mali tribe from Andhra Pradesh, India. Int J Anthropol, 17: 7-16.

Bhasin MK, Kshatriya G 1990. Fertility and mortality differentials among the different groups of Sikkim, India. J Hum Ecol, 1: 267-276.

Bhasin MK, Nag S 2007. A demographic profile of the people of Jammu and Kashmir: 4. Selection intensity. Anthropologist, 9: 93-97.

Bhasin MK, Nag S 2002. Demography of the tribal groups of Rajasthan: 4. Selection intensity. J Hum Ecol, 13: 141-146.

Cavalli-Sforza LL, Bodmer WF 1971. The Genetics of Human Populations. San Francisco: W.H. Freeman.

Crow JF 1958. Index of total selection intensity. Some possibilities for measuring selection intensities in man. Hum Biol, 30: 1-3.

Fisher RA 1958. The Genetic Theory of Natural Selection. New York: Dover.

Johnston FE, Kensinger KM 1971. Fertility and mortality differentials and their implications for micro evolutionary change among Cashinahua. Hum Biol, 43: 356-364.

Reddy BM, Chopra VP 1990. Opportunity for natural selection among the Indian populations. Am J Phys Anthropol, 83: 281-296.

Reddy BM, Chopra VP, Malhotra KC 1987. Opportunity for natural selection with special reference to population structural measures among the Vadde. Ann Hum Biol, 14: 249-261.

Reddy VR, Reddy BKC 1984. Selection Intensities among the Reddis of Chittor district of Andhra Pradesh. India. Comp Physiol Ecol, 9: 33-36.

Spuhler JN 1976. The maximum opportunity for natural selection in some human populations. In: EBS Zubro (Ed.). Demographic Anthropology, Quantitative Approach. Albuquerque: University of New Mexico Press, pp. 185-226.

Sudhakar G, Padma V, Babu BV 1998. Opportunity for natural selection in Koppala Velama caste of West Godavari district, Andhra Pradesh, South Asian Anthropologist, 19: 107-109. 